\title{
Joseph Beuys'un Anısına: 1980'lerden Bir Sergi ve İzmir Çağdaş Sanat Ortamına Etkisi
}

\author{
In the Memory of Joseph Beuys: An Exhibition from the 1980s and Its Impact on the \\ Izmir Contemporary Art Scene
}

\section{Rabia Özgül Kılınçarslan* (]}

\section{Öz}

1980’li yıllarda Türkiye kültür ve sanat sahnesindeki önemli tartışmalardan biri, sanatın ticarileşmesidir. Sanatın ticarileşmesinin sonuçlarından biri de sanat eserinin dekoratif bir objeye dönüşmesidir. Bu soruna çözüm olarak geleneksel araçlarla üretilen bir sanat eseri yerine, sanat piyasasının taleplerinin dışında kalan bir sanatsal pratik önerilmiştir. Bu sanatsal pratiğin nasıl ve hangi araçlarla oluşturulacağı sorusu, sanatçıların alternatif sanatsal arayışlarını ortaya çıkarmıştır. 1986 yılında İzmir Alman Kültür Merkezinde gerçekleştirilen Joseph Beuys’un Anısına Bir Başka Sanat Toplu Sergi Gösteri sergisi, bu tartışmaları anlamak açısından önemli bir örnektir. Artistik pratiğiyle çağdaş sanatın dilini belirleyen önemli sanatçılardan biri olan Joseph Beuys, sanat ile hayat arasındaki sınırı bulanıklaştırmış, sanat disiplinlerinin alanını sosyal heykel kavramıyla genişletmiştir. İzmir kültür sanat ortamında, alternatif sanat pratiklerinin sergilendiği ilk grup sergisi olması, serginin sanat tarihi kronolojisi içindeki yerini belirlemektedir. Sergide yer alan sanatçıların bazıları, 1980'li yıllarda Türkiye'de sergilenen alternatif sanat çalışmalarını ve kavramsal sanat eserlerini üreten ve kavramsal sanatın dilini belirleyen sanatçılardır.

Bu çalışmanın amacı, görsel sanatların üretim şartlarında yaşanan son derece önemli bir tarihsel kaymayı gösteren Joseph Beuys'un Anısına Bir Başka Sanat Toplu Sergi Gösteri sergisinin daha önce ele alınmamış içeriğini aktarmak ve sanat tarihî bakımından önemini ortaya koymaktır.

Anahtar Kelimeler

Çağdaş Sanat, 1980’ler, Joseph Beuys, Cengiz Çekil, İzmir

\section{Abstract}

In the 1980s, one of the most important debates in the arts and culture scene in Turkey is the commercialization of art. One of the results of the commercialization of art is the transformation of the work of art into a decorative object. As a solution to this problem, instead of a work of art produced by traditional mediums, an artistic practice outside the demands of the art market has been proposed. The question of how and with which mediums to create this artistic practice has brought out alternative artistic tendencies. Held in 1986 at the Izmir German Cultural Center, Another Art Collective Exhibition in the Memory of Joseph Beuys exhibition is an important example to understand these discussions. Joseph Beuys, one of the important artists who determined the language of contemporary art with his artistic practice, blurred the border between art and life and expanded the field of art disciplines with the concept of social sculpture. The fact that it is the first group exhibition in the Izmir culture and arts environment where alternative art practices are exhibited determines the place of the exhibition in the art history chronology. The aim of this study is to convey the previously unwritten content of the exhibition, which shows an extremely important historical shift in visual art practices, and to reveal its art-historical importance.

\section{Keywords}

Contemporary Art, 1980s, Joseph Beuys, Cengiz Çekil, İzmir

** Sorumlu Yazar: Rabia Özgül Kılınçarslan (Dr. Öğr. Üyesi), İzmir Ekonomi Üniversitesi, Güzel Sanatlar ve Tasarım Fakültesi, Görsel İletişim Tasarımı Bölümü, İzmir, Türkiye. E-posta: ozgul.kilincarslan@ieu.edu.tr ORCID: 0000-0001-9963-2208

Atıf: Kilincarslan, Rabia Ozgul. "Joseph Beuys'un Anısına: 1980’lerden Bir Sergi ve İzmir Çağdaş Sanat Ortamına Etkisi." Art-Sanat, 17(2022): 275-298. https://doi.org/10.26650/artsanat.2022.17.984180 


\section{Extended Summary}

In Memory of Joseph Beuys An Another Art Joint Exhibition Show event, one of the important examples to understand and rethink the 1980s, when alternative approaches started in the art of Turkey, took place between March $10^{\text {th }}$ and $23^{\text {rd }}, 1986$ in Izmir German Cultural Center. The emergence of the exhibition, the manifesto of the exhibition, and the motivation of the artists to participate are the opposite of the commercialization criticism of contemporary art today. This study which discusses the exhibition, a first for the emergence dynamics of contemporary art in Turkey in the 1980s and the culture and art scene in Izmir, has been carried out by using primary and secondary sources. In this study, the materials, showing the discourse of the exhibition, documents, showing the exhibition setup, and the works of the artists were examined. An interview was made with the artist Vahap Avsar, who took part in the exhibition setup and the exhibition. These collected data were evaluated within the art discussions of the 1980s.

Turkish contemporary art history researches usually focus on the singular narrative mainly, for reasons of the lack of Turkey's chronological study of contemporary art, archives, and documents, and the inability to establish a link between the cases that are disconnected with each other and with actors. In addition to these studies, the works that are made by focusing on thematic exhibitions also serve as a source for the historical narrative. In this respect, group exhibition, which is a collective event where artists come together around a certain discourse, is important in terms of understanding and positioning the artistic debates of that period. It is the first group exhibition in the Izmir culture and art scene where alternative and new artistic trends take place. It partially has basic features such as discourse partnership, material and technical partnership, and form commonality, which we can see in one or more of the group exhibitions. The fact that group exhibitions have a common artistic approach and discourse, which are presented as a manifesto and have an avant-garde proposition, enables us to easily mark these exhibitions in a chronological study of art history. Discourse partnership, that is, the partnership in aesthetic and ethical values can be examined through the explanation of "common minimum" in the exhibition manifesto.

At the exhibition, alongside the works with artistic expression fields such as collage, photography, painting, and printing that have already proved their majority; we see that some of the works in these fields are exhibited together when conceptual art and installation art did not yet become one of the important expression areas of contemporary art in the 1980s. Although we do not find it difficult to accept such an exhibition as a contemporary art exhibition today, the coexistence of these approaches for the 1980s can be described as both a bit contradictory and avant-garde. In the 1980s, they criticized the negativities such as the artistic desensitization, created by similar works on the taste in artistic activities, the transformation of the artwork into 
a decorative object, and/or a commercial commodity. They underlined that artwork is an artistic and cultural communication tool.

In the field of fine arts, it is inevitable to talk about the impact of the Istanbul State Academy of Fine Arts in Turkey. It is possible to observe that the effects of periodic differences and lifestyles on which this effect began to lose its power in the 1980s directly reflected on the art environment. The decrease of state support for culture and art and the oppressive attitude of the political environment to opposing discourses affected the discussions in the culture and arts environment. In these years, when the number of private galleries increased, banks started to open branch galleries in other provinces besides Istanbul and Ankara. Bank collections have had an important effect on the formation of the art market. Private galleries, which opened one after another in the 1980s, also affected the art market. Galleries have played a very important role in increasing the number of collectors, sales of their works, and promoting the artists.

After 1980, the changes in Turkey's cultural and artistic environment's reflection have been seen in Izmir. In the Izmir culture and art environment, there are a limited number of private galleries such as Vakko Gallery, private bank galleries (Isbank, Yap 1 Kredi, Esbank, Ziraat Bank, etc.), as well as the galleries of the cultural centers of local administrations and universities in the 1980s. However, in this period, artworks for plastic arts, painting, and sculpture are seen in exhibitions in Izmir. Some artists-academics who studied abroad and met alternative trends in art, such as Erdag Aksel, Cengiz Cekil, and Ann Aksel (Dorsey), who also took part in the "In Memory of Joseph Beuys" exhibition, were influential in the development of contemporary art in Izmir in the 1980s. It is the first group exhibition where conceptual art examples and alternative art practices are exhibited in the Izmir culture and art environment. A significant number of artists (Necati Abacı, Halil Akdeniz, Ann B. Aksel, Erdağ Aksel, Turgut Aldemir, Hüseyin B. Alptekin, Vahap Avşar, Zafer Aytekin, Canan Beykal, Michael Bishop, Lynn Criswell, Cengiz Çekil, Osman Dinç, Ahmet Elhan, Ayşe Erkmen, Adem Genç, Serhat Kiraz, Ahmet Koman, Füsun Onur, Ahmet Öktem, Mümtaz Sağlam, Fevzi Saydam, Sarkis, Yusuf Taktak) in the exhibition are the founding actors of the contemporary art scene of Turkey. Another importance of the "In Memory of Joseph Beuys Exhibition" is that it is the first exhibition of Huseyin Bahri Alptekin, an important artist in Turkish contemporary art. It is important that the Collective Exhibition I and Collective Exhibition II, held at the Turkish American Cultural Association, is a continuation of this exhibition and that some of the artists, participating in this exhibition, continue their joint search for new trends with these exhibitions. 


\section{Giriş}

Çağdaş sanata dair tanımlar, ortaya koyduğu üretimler gibi dağınıktır. Çağdaş sanatın tarihsel olarak modern sanatın içinden çıktığı görüşü, avangart, kavramsal sanat, postmodern sanat gibi tanımları da kapsayan geniş bir alanın tarifiyle uyumludur. Sanatsal değerin kaynağı üzerinden modern/çağdaş paradigmayı ayıran Nathalie Heinich, çağdaş sanatın gelişimini, sınırların ihlali ve kendi alanını olağanüstü derecede genişletme olarak yorumlamıştır'. Sanatın genişleyen alanı fikri, Rosalind Krauss'un 1979 yazdığ 1 "Sculpture in the Expanded Field"² başlıklı makalesinde yaptığı enstalasyon tanımını anımsatmaktadır. Nasıl çoğu zaman resim ve heykel geleneksel araçlar olarak görülüp klasik sanatın anlatım dili sayılıyorsa, enstalasyon da farklı ara ve teknikleri de içererek çağdaş sanatın anlatım dili kabul edilebilir. Boris Groys, "Politics of Installation" başlıklı makalesinde, günümüzde sanat yapmak ve sanatı sergilemek arasında artık "ontolojik" bir fark olmadığını söylemektedir ${ }^{3}$ Sanat yapmak ve sanatı sergilemek ontolojik olarak ayrılmadığında, sanatçı ve küratör arasında bir ayrım yapılabilir mi sorusu ortaya çıkmaktadır. Groys, eşit estetik hakların mantığını kursa da küratörle sanatçıyı eşitlemez. Ona göre sanat olmayan bir şeyi, gösterme eylemiyle sanata dönüştüren sihirli değneğe sahip kişi, kültürel geleneklere göre hâlâ sanatçıdır . Çağdaş sanatın 1990'larda sanat dünyasındaki yükselişi ve yaygınlaşması sonrasında, 2000'lerin başında Türkiye'de en çok tartışılan konulardan biri küratörün rolüne ilişkindir 5 .

Çağdaş sanata dair en önemli eleştirilerden biri onun küresel sermaye ile olan ilişkisidir ${ }^{6}$. 1980'ler sonrasında şirketlerin çağdaş sanata müdahalesi, Chin-tao Wu'nun Kültürün Özelleştirilmesi kitabında ayrıntılı bir biçimde örneklendirilmektedir. ABD'de Reagan, İngiltere'de Thatcher dönemlerinde kamu politikasında gerçekleşen değişimler ve sanat kurumlarının işletme kültürüne angaje olması süreci çağdaş sanatın gelişim sürecinde belirleyicidir ${ }^{7}$. 1980'lerde Türkiye kültür sanat ortamının çağdaş sanatın çıkışını da belirleyen en önemli tartışmalarından biri özel sektör ve kamu destekleri üzerinedir.

1 Mario Perniola, Sanat ve Gölgesi - Sanattan Geriye Ne Kaldr?, çev. Kemal Atakay (İstanbul: İletişim Yayınlar1, 2015), 79-80.

2 Rosalind Krauss, "Sculpture in the Expanded Field", The Anti-Aesthetic-Essay on Postmodern Culture, ed. Hal Foster (Seattle: Bay Press, 1993), 31-42.

3 Boris Groys, "Politics of Installation," e-flux Journal 2 (Ocak 2009), 2, erişim 25 Aralık 2021, http://www.eflux.com/journal/politics-of-installation/.

4 Boris Groys, Art Power (London: MIT Press, 2008), 13-53.

5 Türkiye'de 2000'lerin başında küratörlük üzerine yapılan tartışmalar için şu kaynaklara bakılabilir: Enis Batur, "Küratörün Sinırında," Sanat Dünyamız 81(2001), 95-96; Samih Rifat, "Nedir, Neyin Nesidir Küratör? Ya da Senaryo Yazarı Yönetmenliğe Soyunmalı mı?," Sanat Dünyamız 81 (2001), 97-100; Ahu Antmen, “Küratörün 'Ne' Olduğunu Neden Tartışıoruz?," Sanat Dünyamız, 81 (2001), 101-105; Beral Madra, “Küratörlüğün Sınırı Nedir?”, Radikal Gazetesi, 27 Temmuz 2001, erişim 25 Aralık 2021, https://www. beralmadra.net/articles/radikal-gazetesi/kuratorlugun-siniri-nedir/.

6 Julian Stallabrass, Sanat A.Ş. - Çağdaş Sanat ve Bienaller (İstanbul: İletişim Yayınları, 2009), 13-17.

7 Chin-Tao Wu, Kültürün Özelleştirilmesi-1980’ler Sonrasinda Şirketlerin Sanata Müdahalesi (İstanbul: İletişim Yayınları, 2005) 86- 107. 
Bu çalışmanın odaklandığı Joseph Beuys'un Anısına Bir Başka Sanat Toplu Sergi Gösteri ${ }^{8}$ etkinliği, 1980'lerde sanat ortamındaki tartışmaları da kendine mesele edinerek çağdaş sanatın önemli figürlerinden biri olan Joseph Beuys'un 1986'da ölümü üzerine düzenlenmiştir. Serginin düzenlenmesinden yaklaşık kırk yıl sonra çağdaş sanatın gelişimi ve eğilimleri, serginin düzenlendiği dönemdeki kaygılardan farklı yönlere kaysa da Türkiye'de çağdaş sanattın gelişim dinamiklerini anlamak açısından Joseph Beus'un Anısına sergisini kayda geçirmek önemlidir. Bu çalışmanın amacı, görsel sanatların üretim şartlarında yaşanan son derece önemli bir tarihsel kaymayı gösteren bu serginin daha önce yazılmamış olan içeriğini aktarmak ve sanat tarihsel önemini ortaya koymaktır.

Çağdaş sanatın birbirinden kopuk gelişen olgu ve aktörleri arasında kurulan bağlarla yazılan tarihi, Türkiye çağdaş sanatı söz konusu olduğunda yeterli arşiv ve belgenin bulunmaması, bu alanda yapılmış akademik çalışmaların azlığı gibi sebeplerle kronolojik bir çalışmayı zorlaştırmaktadır. Eser ve sanatçılara odaklanarak aşılmaya çalışılan bu zorluk için önemli kaynaklardan biri de sanatçıların belirli bir tematik bağlam etrafında bir araya geldiği kolektif ortamlardır ${ }^{9}$ Eser ve sanatçı odaklı araştırmaların dışında kolektif ortamlar olan sergileri de araştırmanın merkezine almak dönemin sanat ortamını ve anlayışını kavramada önemli kaynaklardan biri olabilir. Çalışmanın hedeflerinden biri de Türkiye'deki çağdaş sanat üretimlerine dair yapılacak yeni çalı̧̧malara kaynaklık etmektir. Bu çalışmada, serginin söylemini gösteren materyaller, sergi kurulumunu gösteren belgeler ve sanatçıların çalışmaları incelenmiştir. Toplanan veriler, dönemin sanatsal dinamikleriyle birlikte değerlendirilmiştir. Serginin kurucusu Cengiz Çekil'in monografisi, Cengiz Çekil'in sergi broşüründe yazdığı manifesto ve Beuys üzerine diğer metinleri incelenmiştir. Çekil'in sergi kurulum sürecinde asistanı ve sergide yer alan sanatçılardan biri olan Vahap Avşar'la yapılan sözlü görüşme de çalışmaya eklenmiştir. Sergide yer alan diğer sanatçıların arşivleri de çalışmaya kaynaklık etmiştir. Serhat Kiraz ve Hüseyin Bahri Alptekin'in Salt Araştırma Arşivi'nde yer alan sergi fotoğrafları, sergiye ait görsellerin kaynağını oluşturmaktadır. Türkiye'de görsel sanatların üretim dilindeki önemli bir değişimini gösteren serginin içeriği, sergi materyalleri, sanatçı konuşmaları kaydı, röportajlardan elde edilen bilgilerle aktarılmış ve sanat üretimindeki değişim, sergide yer alan bazı çalışmalar üzerinden ele alınmıştır.

Serginin Joseph Beuys'un anısına düzenlenmiş olması sergide yer alan çalışmaların benzer bir pratikte üretimler olup olmadığı sorusunu akla getirmektedir. Sergide yer alan sanatçılardan bu yönde bir çalışma üretmesi beklenmemiştir. Fakat Beuys'un "ben şeyleri bir başka biçimde görmeyi bulmak isterdim. Sanatın yeni bir yönünde

8 Çalışmanın devamında serginin adı kısaca "Joseph Beuys'un Anısına" olarak kullanılacaktır.

9 Süreyya Evren, "Türkiye Güncel Sanatı Tarihini Nasıl Yazmalı," Kullanma Kılavuzu 2.0: Türkiye'de Güncel Sanat 1975-2015 (İstanbul: art-ist ve Revolver yayıncılık, 2015), 11-17. 
çalışıyor ve insanın her yaptığının sanat olduğunu kanıtlamak istiyorum"10 sözlerine sergi broşüründe yer verilmiştir. Bu bakımdan düzenlenen sergi, Beuys’un sanatsal fikirlerinden tümüyle bağımsız değildir.

Artur Danto, Sanatın Sonundan Sonra kitabında Andy Warhol'la birlikte Joseph Beuys'tan zamanın en etkili iki sanat düşünürü olarak bahseder. Danto, bu yargısını Clement Greenberg'in sanat eleştirmeni olarak kaybettiği güç ve Warhol'la Beuys'un herhangi bir şey sanat yapıtı olabilir, sanat yapıtları hiçbir özel biçimde görünmek zorunda değildir; herkes sanatçı olabilir fikirlerini savunan sanatsal üretimleri üzerinden açıklamıştır ${ }^{11}$. Danto'nun tarifiyle Greenberg epizodu ${ }^{12}$ bitmiştir. Sanat yapıtının hiçbir özel biçimde olmak zorunda olmadığını kabul eden bir anlayışla birlikte sanatın felsefi kimlik arayışı tarihi de son bulmuştur. Ona göre 1980'lerde sanatın sonunu getiren şey sanat üretiminin bitmesi değil anlatısal olarak yapılandırılmış sanat tarihinin sona ermesidir ${ }^{13}$. Tony Godfrey, Danto'nun argümanını reddetmez fakat bu konuda Warhol ve Beuys'tan çok Art \& Language'in kurucularından Terry Atkinson'un, Joseph Kosuth'un ve Bruce Nauman'ın çalışmalarından örnekler vermiştir. Bu sanatçıların tümüyle bilinçli olarak felsefe yapar gibi hareket ettiklerini vurgulamıştır ${ }^{14}$.

Beuys’un 1963 tarihli sahneye çıkıp iki müzisyenden oluşan müzik kutusunu kurması ve şarkı bitene kadar sahnede durup müziği dinlediği performansı, Fluxus'la ilişkili olduğu döneme denk düşmektedir. Godfrey, Beuys’un bu performansını da örnekleyerek, Fluxus eylemlerinin Dada performanslarıyla karşılaştırıldığında yenilikçi olmadığını fakat epey teatral olduğunu belirtmiştir. Benzer şekilde Arte Povera'y1 ${ }^{15}$ da kavramsal sanatın bir çeşidi kabulünden yola çıkarak Beuys'un 1963 tarihli "Fat Chair"16 çalışmasının hazır-yapıt özelliklerini analiz etmiştir. George Brecht veya

10 “Joseph Beuys'un Anısına sergi broşürü,” SALT Araştırma Cengiz Çekil Arşivi, erişim 17 Ocak 2020. https:// archives.saltresearch.org/handle/123456789/51404

11 Arthur C. Danto, Sanatın Sonundan Sonra-Çağdaş Sanat ve Tarihin Sınır Çizgisi, çev. Zeynep Demirsu, (İstanbul: Ayrıntı Yayınları, 2010), 121.

12 Arthur Danto, Batı sanatının tarihini Vasari epizodu ve Greenberg epizodu olarak ikiye ayırır. Danto’ya göre Vasari epizodu, sanatı temsil olarak yorumlayan anlayışı ifade eder ve filmin resimden çok daha başarılı bir biçimde gerçekliği betimleyebilmesiyle sona erer. Greenberg epizodu, sanatsal medyumun ayırt edici koşullarıyla özellikle resim üzerinden tanımlanır ve sanatın belirleyici şartlarını bu yolla ifade eder. Bu anlatı dizgesi sanat yapıtı hiçbir özel biçimde olma zorunluluğu taşımadığında bitmiştir.

13 Danto, Sanatın Sonundan Sonra-Çăgdaş Sanat ve Tarihin Sınır Çizgisi, 159.

14 Tony Godfrey, Conceptual Art (London: Phaidon,1998), 97.

15 Kelime anlamı yoksul sanat olan Arte Povera, sıradan, gündelik malzemelerle sanat üretimini savunur. 1960'ların sonu, 1970'lerin başında Giovanni Anselmo, Alighiero Boetti, Pier Paolo Calzolari, Luciano Fabro, Jannis Kounellis, Mario Merz, Guilio Paolini and Michalengelo Pistoletto sanatçıların yer aldığı sergileri Milanolu eleştirmen Germano Celant, “Arte Povera” olarak tanımlamıştır. Sıradan malzemelerle, sanatın temellerine dair bir araştırma yaklaşımını benimseyen Arte Povera sanatçıları, bu araştırmada analitik bir yaklaşımdan çok şiirsel bir yaklaşımla en basit malzemelerle endüstrileşen topluma ve teknolojik dünyaya seslenirler.

16 1964-1985 yılları arasında farklı şekillerde karşımıza çıkan "Fat Chair" sandalye, yağ, yün kimi zaman cam vitrin ya da başka malzemelerle yapılmış bir seri çalışmaya verilen isimdir. Bu çalışmanın kendi anlatısını zaman içinde geçirdiği değişimlerle anlatması Beuys’un mit yaratma yaklaşımına da uygundur. Kosuth'un sandalyenin tanımını araştırırken sanatın ne olduğunu sorgulamasıyla Beuys'un kendi evrenini, anlatısını yaratan sandalyesiyle sanatı tanımlaması arasındaki fark kavramsal sanatla çağdaş sanatın bağlantısını anlamamıza yardımcı olabilir. 
Joseph Kosuth'un sandalyeleriyle karşılaştırarak onun sandalyesini hazır-yapıttan çok heykele benzetmiştir. Godfrey'a göre Beuys'un "Fat Chair" çalışması Reliklerin (kutsal nesnelerin) taşıdığı hikâyeci yaklaşıma sahiptir. Bu nedenle geleneksel sanatın temsiliyet anlayışına yakın durmaktadır. Godfrey ayrıca Beuys'un çalışmalarının kendi mitleri ve öğretilerini merkeze aldığını, Kavramsal Sanat'ın anti-otografik ve rasyonel nesne yaratma eğilimine ters olduğunu vurgulamıştır ${ }^{17}$.

Danto'nun çağdaş sanat üretimlerini tanımlamada kurumsal bir yapı olarak temel aldığ 1 sanat dünyası kavramı, sanat yapıtlarına yapılan estetik yargılamayı evrensel bir kategori olmaktan çıkarmıştır. Danto'nun sanat dünyası, yeni ve farklı sanatsal etkinliklerin kümelendiği, eserlerde mutlak ve değişmeyen ortak kriterler aramaya gerek bırakmayan bağlamsal bir ortamdır. Bu sanat atmosferi, Godfrey'da sanatın devrimci ya da yıkıcı karakterinin asgariye indirgendiği bir yerdir. Çağdaş dünyada bütünleyici ve belirleyici bir faktör olmaktan ziyade ayrı bir alemi temsil etmektedir. Godfrey çağdaş sanatla kavramsal sanatı ayırırken sanat dünyası kavramına, farklı ve gizemli bir anlam yüklendiğinin altını çizmektedir ${ }^{18}$. Malzemeden ve biçimden kopuş, düşünceyi ve anlam arayışını öne çıkarma bağlamında çağdaş sanat ve kavramsal sanat birbirine yaklaşmaktadır. Çağdaş sanatın hikâyeci ve otobiyografik olana yönelmesi, değerlendirmeye yönelik belirli kategorilerin önerilmemesi ya da her şeyi mümkün kılan kapsayıcılığıyla sanatın devrimci ve yıkıcı karakterini kaybetmesi, sanatın özerlik arayışını 1lımlı özerlik noktasına çekmiştir.

Resmin ölümü ya da sanatın sonu, çağdaş sanat ve kavramsal sanat üzerine olan bu tartışmalar, Türkiye'de 1980'lerin ikinci yarısında başlamış ve 1990'larda epeyce hararetlenmiştir. O dönemde, Türkiye'de görsel sanatlar alanına has çağdaş sanat ve güncel sanat tanımlamaları birbiriyle yarışmaktadır. Çağdaş, daha muhafazakâr, ulusalc1, bürokratik devlet merkezli bir söyleme atfedilirken; güncel daha yenilikçi ve birbirine benzemeyen ögelerin daha rahat yan yana getirilebildiği bir alanın tarifi olarak kullanılmaya başlanmıştır. Çağdaşlık kavramı ve çağdaş olanın ne olduğu Batı'da da tartışılmaktadır. Fakat çeviri değişikliği yoluyla yapılan anlamsal bir ayrıştırma bulunmamaktadir ${ }^{19}$.

\section{1980'lerde Türkiye'de Çağdaş Sanat}

Türkiye sanatındaki alternatif yaklaşımların başladığı 1980'ler, geleneksel sanat disiplinleri olan resim ve heykelle çağdaş sanatın karşı karşıya geldiği ilk dönemlerdir. Bu döneme ait sınırlı sayıda kaynak çalışma bulunmaktadır. Sanatçılar üzerinden yapılan çalışmalar kadar sanatçıların bir araya geldiği müşterek alanlar olan sergiler

17 Godfrey, Conceptual Art, 184.

18 Godfrey, Conceptual Art, 251.

19 Elçin Gen, "Çağdaştan Güncele, Eserden İşe: Bir Çeviri Hikayesi.” E-Skop, 7. 8. 2012, erişim 25 Aralık 2021, https:/www.e-skop.com/skopbulten/cagdastan-guncele-eserden-ise-bir-ceviri-hikayesi/847 
üzerine yapılacak çalışmalar da Türkiye'de çağdaş sanatın gelişimini anlamamıza yardımcı olacaktır. 1970'lerde işaretleri görülen, 1980'lerde yaygınlaşan ve 1990'larda görsel sanatlar alanında kırılmaları gerçekleştiren ve bu çizgideki çalışmalarını 2000 'lerde de sürdüren sanatçılar arasında değerlendirilen kimi sanatçılar bu çalışmanın odağındaki Joseph Beuys 'un Anısına sergisine de katılmışlardır ${ }^{20}$. Bu sanatçıların birçok sergide bir araya geldiği ve bu anlamda sergilerin de bir süreklilik içinde değerlendirebileceği söylenebilir ${ }^{21}$. Yine birçok kaynak, Türkiye'de çağdaş sanatın tarihini 1950'lerde ve 1960'larda yapılan tekil üretimleri ayırarak 1970'lerin ortalarında başlayan Yeni Eğilimler ${ }^{22}$ sergileriyle başlatmaktadır ${ }^{23}$. İstanbul Sanat Festivali (1977-1987) kapsamında düzenlenen Yeni Eğilimler Sergisi, sanat ortamında gündemde kalacak önemli sanatsal tartışmalara ve 1990'lar sanatının seyrinde etkili olacak oluşumlara zemin hazırlamıştır. ${ }^{24}$

Sanatta alternatif eğilimleri temsil eden çalışmalarla, çağdaş sanat etkinliklerinin ilklerine sahne olmuş 1980'ler, Türkiye'nin siyasal, toplumsal ve kültürel hayatında kırılmaların olduğu bir dönemdir. Istanbul Sanat Festivali etkinlikleri, Devlet Güzel Sanatlar Akademisi tarafından çağdaş sanat ortamının dinamiğini belirlemek, sanatı toplumun farklı kesimleriyle paylaşmak amacıyla düzenlenmiştir. Tüm disiplinlere yer veren, çağdaş olanı belirlemeye yönelik bu etkinlikler, sürekli hâle gelerek Yeni Eğilimler Sergisi adı altında gerçekleştirilmiştir. ${ }^{25} \mathrm{Bu}$ sergilerin ilk üçüne katılanlar arasında Şükrü Aysan, Osman Dinç, Serhat Kiraz, Cengiz Çekil, Canan Beykal, Ayşe Erkmen, Füsun Onur, Gürel Yontan ve Gülsün Karamustafa vardır. Bu sanatçılardan Osman Dinç, Serhat Kiraz, Cengiz Çekil, Canan Beykal, Ayşe Erkmen, Füsun Onur bu çalışmada incelenen "Joseph Beuys'un Anısına Bir Başka Sanat Toplu Sergi Gösteri” etkinliğinde de yer almışlardır. Bütün bu sanatçılar geleneksel resim ve heykel dilini tümüyle dışlamadan, serginin amacına uygun ve izleyiciyi şaşırtan, çağdaş sanat eğilimlerini yansıtan çalışmalar üretmişlerdir. ${ }^{26}$

Çağdaş sanatın toplumsal, ekonomik ve teknolojik değişimlerle yakın ilişkisinin yanı sıra dönemin siyasi dinamiklerin etkisi de önemlidir. Sanat ekonomisindeki değişim, siyasi ortamın etkisi -toplumsal özgürlük ve refah- sanat ortamını etkilerken

20 İpek Duben ve Esra Yıldız, Seksenlerde Türkiye'de Çağdaş Sanat:Yeni Açıllımlar (İstanbul: Bilgi Üniversitesi Yayınları, 2008), 10.

21 Sergiyi düzenleyen Cengiz Çekil, Erdağ Aksel gibi isimlerin yanı sıra sergiye katılan Osman Dinç, Ayşe Erkmen, Serhat Kiraz, Füsun Onur, Saydam, Sarkis gibi sanatçılar Seksenlerde Türkiye'de Çağdaş Sanat: Yeni Açılımlar kitabında ele alınan sanatçılardır.

22 Güler Bek, "1970-1980 Yilları Arasında Türkiye'de Kültürel ve Sanatsal Ortam” (Doktora tezi, Hacettepe Üniversitesi, 2007), 14.

23 Evren, "Türkiye Güncel Sanatı Tarihini Nasıl Yazmalı", 11-17.

24 Bek, "1970-1980 Yılları Arasında Türkiye'de Kültürel ve Sanatsal Ortam,” 156.

25 Vasıf Kortun, 20 (İstanbul: SALT/Garanti Kültür AŞ, 2018), 167, erişim 17 Ekim 2020, https://saltonline. org/tr/1773/20 erişim 17 Ekim 2020.

26 Nancy Atakan, Araylşlar-Resimde ve Heykelde Alternatif Akımlar (İstanbul: Yapı Kredi Kültür Yayınevi, 1998), 13. 
sanat ortamı da siyasi ortamdaki değişimleri ve krizleri eserlere taşımıştır. "1990’lar Üzerine Yeniden Düşünüş” başlıklı yazısında Vasıf Kortun, 1980 askerî darbesinin hemen ardından Türkiye kültür ortamında birçok temel meselenin netlik kazandığını belirtmiştir. Kortun, ulus ötesi bir perspektiften bakılması gereken 1990'lara gelmeden önce 1980’lere bakmayı önermektedir. 1980’leri, sanatsal meselelerin dönemin siyasi şartlarından kaynaklanan ortamla şekillendiği, devlet güdümlü sanat anlayışlarından ayrışan daha özerk ve bağımsız bir kültür sektörünün oluşmaya başladığı bir dönem olarak tanımlamıştır ${ }^{27}$. Günümüz Sanatçıları Ístanbul Sergileri, 1984’te başlayan Öncü Türk Sanatından Bir Kesit ile A,B,C,D (1989-1992) sergileri bu özerkleşme alanında ve bir devamlılık çizgisinde ele alınmışs ${ }^{28}$ ve 1980 'lerde sanatta alternatif araylşların sonuçları olarak görülmüştür ${ }^{29}$.

Yeni Eğilimler Sergisi, alternatif sanat arayışlarına alan açan bir etkinlik olmanın ötesine geçmiş, 1981'e gelindiğinde ülke çapında haberi yapılan, önemli bir etkinlik hâline dönüşmüştür ${ }^{30}$. Serginin uluslararası niteliği, Cumhuriyet sonrası sanat ortamında uzun süredir devam eden ulusallık-evrensellik tartışmalarını başka bir noktaya taşımıştır ${ }^{31}$. Bu tartışmalar, 1980'lere gelindiğinde kavramsal sanat çalışmaları, alternatif sanat yaklaşımları ve uluslararası etkinliklerin artmasıyla farklı bir bağlam kazanmıştır. Batı sanat tarihiyle resim ve heykel yoluyla bir türlü yakalanamayan eşzamanlılık, çağdaş sanatla yakalanabilir mi sorusu tartışılmaktadır.

İstanbul Kültür Sanat Vakfı'nın desteklediği Uluslararası İstanbul Festivali etkinlikleri 1980'li yıllarda kurumlaşma ve sponsorluk kavramlarının yerleşmesiyle, İstanbul Bienali'ne (1987) dönüşmüştür. Bu etkinlik, devlet-özel sektör iş birliğinin önemli örneklerindendir. Devlet desteği, bilet satışları gibi gelirlerin yanı sıra özel sektörün desteğinin önem kazandığı bu etkinlik, 1980'lerde oluşmaya başlayan kültür sanat piyasasının bir başka göstergesidir. Etkinlik, Türkiye'de çağdaş sanatın kurumlaşmasında, sponsorluk anlayışının oluşmasında ve buna bağlı olarak sanatın özerkleşmesinde önemli bir adım olarak görülmüştür. Kimi sanat çevreleri festivali, kültürel emperyalizmin bir sonucu olarak eleştirirken kimileri de halka açık bir etkinlik düzenlemek amacıyla belirsiz ve plansız, amaç ve ideallerinden uzaklaşmış bir etkinlik olarak eleştirmiştir. 1970'li y1llarda İstanbul Festivali'nin elit bir kesime hatta burjuvaziye hitap ettiği, etkinliğin merkezî fakat topluma yayılmamış olduğu tartışmalarının devam ettiği yıllarda Ankara, İzmir ve İstanbul dışındaki kentlerde, yerel yönetimler festivaller düzenlemeye başlamıştır ${ }^{32}$. Liberal ekonomiyle de uyumlu bu yaklaşım, sanatın özerkleşmesi için alternatif, muhalif olanın destek bulabileceği

27 Vasıf Kortun, 20 (İstanbul: SALT/Garanti Kültür AŞ, 2018), 21.

28 Ali Akay, Sanatın Sosyolojik Gözü (İstanbul: Bağlam Yayınları, 1999), 67-68.

29 Nancy Atakan, Arayışlar-Resimde ve Heykelde Alternatif Akımlar, 15.

30 Şükrü Aysan, "Uluslararası Sergilemelere Doğru," Hürriyet Gösteri Sanat ve Edebiyat Dergisi 12 (1981), 3.

31 Aysan, "Uluslararası Sergilemelere Doğru," 3.

32 Bek, “1970-1980 Y1lları Arasında Türkiye’de Kültürel ve Sanatsal Ortam,” 144-146. 
bir ortam için bir adım olarak görülmüştür. Aynı zamanda, Cumhuriyet sonrası sanat tartışmalarında yer alan geriden gelme sorununu aşan güncel bir dil, dünya ile eş zamanlılık yakalama firsatı olarak değerlendirilmiştir.

Bir taraftan kültür ve sanat alanında devlet politikalarının yüzeysel olduğu ve vaat düzeyinde kaldığ $1^{33}$ eleştirileri yapılmaktadır. Diğer taraftan ekonomideki liberalleşme sürecinin olumsuz etkileri dile getirilmektedir. Özel sektörün ve özel bankaların da etkin bir şekilde sanat ortamına dâhil olmaları, özel sektör tarafindan desteklenen yeni bir sanatçı tipini ortaya çıkarmışıır' ${ }^{34}$. Joseph Beuys'un Anısına sergisinin broşüründe dile getirilen sanatsal arayış, döneme dair bu eleştirilerin bir yansımasıdır. Hem devlet politikaları hem de özel sektörün etkisini eleştirenler, sorunu, kültür sanat politikasında gelişmeye odaklanmak yerine korumaya odaklanmak olarak nitelendirmektedir ${ }^{35}$. Özel sektörün kültür sanat politikasına etkisinin gelişmeye katkısı olsa da gelişimi, burjuvazinin çıkarlarını koruma sınırında konumlandırdığı, gelişimin itici gücü olan düşünce özgürlüğü ve demokrasi anlayışını belli bir merkezde, sınıfta toplandığ şeklinde eleştirilmektedir ${ }^{36}$. Devlet desteğinin yeterli olmayışı, özel sektörün sanatla ilişkisinin sanatın üretim dinamiklerine olumsuz etkisi ve özel sektör desteklerinin reklam giderlerinin ötesine geçmemesi bu eleştirilerin kaynağını oluşturmaktadır ${ }^{37}$.

1989 yılında, Uluslararası Plastik Sanatlar Birliğine (UNESCO AIAP) bağlı Plastik Sanatlar Derneği kurulmuştur. Derneğin kuruluş amacı, kısıtlı devlet desteği ile özel sektörün belirleyiciliği arasına sıkışan sanatçının sanatsal üretimi için aradığı özerklik alanını savunmaktır. Bu amaç o dönemdeki özerklik tarış̧malarının gündemi ne kadar belirlediğinin bir göstergesidir ${ }^{38}$. Düşünce özgürlüğünün tam olmadığı, sanat piyasasının dengesiz geliştiği bir ortamda yenilikçi ve özgürlükçü tavrı ile çağdaş sanat, alternatif ve eleştirel olarak konumlandırılmıştır. Resim ve heykel gibi geleneksel araçların sanat piyasasında daha kolay dolaşıma girmesi, çağdaş sanatın henüz piyasasının oluşmaması çağdaş sanatın 1980’lerde eleştirel bir dil olarak görülmesine uygundur.

Joseph Beuys'un Anısına sergisinin düzenlendiği yıllarda Beuys'un üretimleri ve sanat görüşü Türkiye kültür-sanat ortamında çok iyi bilinmiyordu. Serginin manifestosunda yer alan eleştirel yaklaşım doğrudan Beuys'un üretim pratiğiyle ilişki kurmamaktadır. Beuys'un esas etkisinin 1990'lı yılların başında olduğunu söyleyebiliriz ${ }^{39}$.

33 Ayşe Nahide Yılmaz, “1980'li Yıllarda Türkiye'de Sanat ve Siyaset İlişkisi”” (Doktora tezi, Hacettepe Üniversitesi, 2014), 38.

34 Beral Madra, İki Yllda Bir Sanat Bienal Yazıları 1987- 2003 (İstanbul: Norgunk Yayınc1lı, 2003), 34.

35 Aziz Çalışlar, "Sanatsal Kültürümüzde ve Sanatta Gelişme Sorunu," Bilim ve Sanat Dergisi 10 (1985), 13.

36 Aziz Çalışlar, "Günümüzde Sanatsal Kültür ve Estetik" Bilim ve Sanat Dergisi 37 (1984), 49.

37 Y1lmaz, "1980’li Yıllarda Türkiye’de Sanat ve Siyaset İlişkisi," 84.

38 Güher Gamze Rastgeldi, "Türkiye’de Çağdaş Sanat Piyasasının Gelişimi: 2001 Krizi ve İktisat Bankası Koleksiyonunun Satılışı”, (Yüksek Lisans tezi, Hacettepe Üniversitesi, 2019), 63.

39 Joseph Beuys'un doğum yıl dönümü nedeniyle Hürriyet Gösteri-Sanat Edebiyat Dergisi sanatçının adına özel bir sayı yayınlamıştır. Derginin Aralık 1991 tarihinde yayımlanan 133. sayısında sanatçının çalışmalarına ve sanat anlayışına ilişkin metinlere yer vermiş̧ir. 
1995 yıllında küratörlüğünü Rene Block'un yaptığı ORIENT/ATION Paradoksal Bir Dünyada Sanatın Görünümü başlıklı 4. İstanbul Bienali'nde Beuys'un çalışmalarının yer alması, Türkiye çağdaş sanatında sanatçıyı daha çok bilinir bir figür hâline getirmiştir. Bundan dolayı, Joseph Beuys 'un Anısına sergisini, çağdaş sanattın tarihinde konumlandırırken doğrudan Beuys'un sanat pratiği ile ilişkilendirmek yerine 1980'lerdeki kültür sanat ortamı içinde değerlendirmek daha doğru olacaktır.

\section{1980'lerde İzmir'de Kültür Sanat Ortamı}

Türkiye kültür ve sanat ortamı 1980 sonrasında geçirdiği değişimin bir yansıması da İzmir'de görülmüştür. İzmir çağdaş sanat ortamında bu konudaki ilk belirleyici sergi, Joseph Beuys'un Anısına sergisidir. 1980'lerde Türkiye kültür sanat ortamının en köklü sanat kurumları sanat eğitimi veren üniversitelerdir. Sanat eğitimi kurumlarının kültür sanat ortamı üzerindeki etkisi belirleyicidir. Geleneksel disiplinler olan resim ve heykelin sınırlarının genişletilmesi ve alternatif arayışların ortaya çıkması, sanat eğitimi kurumlarında tartış11ıordu ${ }^{40}$. 1980'lere gelindiğinde Devlet Güzel Sanatlar Akademisinin gücünü yitirmeye başladığı, dönemsel farklılıkların ve yaşam biçimlerinin etkisinin sanat ortamına doğrudan yansıdığ 1 gözlenmektedir. Kültür sanata devlet desteğinin azalması, siyasi ortamın muhalif söylemlere baskıcı tutumu, çağdaş sanatın çıkışını belirleyen diğer etmenlerdir. İstanbul'da akademiden ayrışan çağdaş sanat, İzmir'de kültür ekonomisinin İstanbul'daki kadar gelişmemiş olması sebebiyle kendisine ancak akademide yer bulmuştur. Akademi çoğunlukla klasik bir anlayışı temsil etmektedir. Alternatif malzeme ve teknikle yapılan bu yeni çalışmalar, akademi, galeri gibi yerleşik kurumların dışında varlık göstermişlerdir. Dokuz Eylül Üniversitesi Güzel Sanatlar Fakültesindeki akademik ortam da bu tartışmalardan etkileniyordu. Geleneksel araçlar dışındaki sanat üretimleri tartışmalı bulunsa da kendisine ifade alanı bulabiliyordu ${ }^{41} .1975$ yılında Ege Üniversitesine bağlı olarak kurulan fakülte, 1981 yılında Dokuz Eylül Üniversitesi bünyesine geçmiştir. Joseph Beuys'un Anısl$n a$ sergisinde de yer alan Erdağ Aksel, Cengiz Çekil, Ann Aksel (Dorsey) gibi yurt dışında eğitim almış, sanatta alternatif eğilimlerle tanışmış sanatçı-akademisyenler, 1980’li yıllarda İzmir'de çağdaş sanatın gelişiminde etkili olmuştur.

1950’lerden sonra Türkiye kültür ve sanat ortamında etkili olan Yabancı Kültür Kurumlar1 ${ }^{42}$, 1980'lerde İzmir'de gerçekleştirilen sergiler açısından önemlidir. Alman Kültür Merkezi ve Türk Amerikan Dostluk Derneği (Amerikan Kültür Merkezi) sergileme imkânı ve mekân sağlayan, yeni anlayışların desteklendiği önemli yabancı kültür kurumlarıdır. 1967 yılında başlayan DYO resim yarışmaları bu yıllarda da sürmüş-

40 Bek, “1970-1980 Yılları Arasında Türkiye'de Kültürel ve Sanatsal Ortam,” 89.

41 Sargon, Nursaç, “İzmir'de Güncel Sanatın Değişimi (1986-2014),” (Yüksek Lisans tezi, Bilgi Üniversitesi, 2016), 13.

42 Zeynep Yasa Yaman, “1950’li Yılların Sanatsal Ortamı ve 'Temsil’ Sorunu”, Toplum ve Bilim 79 (1998), 103. 
tür. Türkiye'nin ilk özel resim müzesi olan Selçuk Yaşar Resim Müzesi 1985 yılında İzmir'de açılmıştır. 1952 yılında Kültürpark’ta açılan İzmir Resim Heykel Müzesi ve Galerisi 1973 'te taşındığı Konak'taki binasında, her yıl düzenlenen devlet sergilerine ev sahipliği yapmaktadır ${ }^{43}$. İzmir kültür sanat ortamında 1980'lerde yerel yönetim ve üniversitelerinin kültür merkezlerinin ve galerinin yanı sıra Vakko Galeri, banka galerileri (İş bankası, Yapı Kredi, Esbank, Ziraat Bankası vb.) gibi sınırlı sayıda özel galeriler yer almaktadır. Özel galerilerin sayılarının arttığı bu yıllarda, bankalar İstanbul ve Ankara dışında başka illerde de şube galerileri açmaya başlamış, özel ve tüzel sanat koleksiyonların sayısında artış olmuştur ${ }^{44}$. Bu dönemdeki sergilerde plastik sanatlar çalışmaları, resim ve heykel görülmektedir. Devlet desteğinden ve akademi şemsiyesinden ayrılan sanatın bu dönemde yeni belirleyicilerinden biri özel sektörün desteğidir. Çağdaş sanat üretimlerinin geleneksel sanat yaklaşımlarına karşı muhalif bir duruşu vardır. Bu yaklaşım kimi zaman devlet güdümlü sanat ve sanatın özerkliği tartışmalarını da kapsamaktadır. Sanatın temel meseleleri üzerine yoğun tartışmaların yapıldı̆̆ı bu dönemde, yeni alternatif eğilimler bağımsız sektörün bir araya gelişiyle ortaya çıkmıştır ve özerklik tartışmalarına yeni bir boyut getirmiştir ${ }^{45}$.

Sergide yer alan sanatçılar arasında Yeni Eğilimler sergilerinin ilk üçüne katılan çağdaş sanat anlayışına sahip sanatçılarla, Dokuz Eylül Üniversitesi Güzel Sanatlar Fakültesinden akademisyen-sanatçı bir topluluk bulunmaktadır. Sanattaki alternatif yaklaşımları, yeni eğilimleri gösteren bu sergi o zamana kadar İzmir kültür sanat ortamının görmeye alışık olduğu sergilerden farklıdır. Cengiz Çekil'i serginin küratörü ${ }^{46}$ olarak nitelendirmek yanlış olmaz. Çekil'in Öncü Türk Sanatından Bir Kesit sergilerine katılmış olması ve İstanbul'daki kavramsal sanat yapan sanatçılarla olan tanışıklı̆̆ bu serginin oluşmasında etkilidir. Joseph Beuys'un genişletilmiş sanat kavramı ya da sosyal plastik yaklaşımı Çekil'in Paris'te öğrencilik yıllarında çalışmalarını etkileyen fikirlerdir. Sanatçının Türkiye'ye döndükten sonra akademik hayatın içinde üretme pratiğinin yavaşladığı ve Beuys'un fikirlerini artık Paris’teki öğrencilik yıllarında olduğu gibi değerlendirmediği görülmektedir. Sanatçının, kültürel farklarla Beuys'un fikirlerine baktığ1, 1990'lardaki yazışmalarında, mektuplarında belirtilmiştir ${ }^{47}$. Çekil, Beuys'u ustası olarak görse de kültürel farklılıklardan dolayı performansın, arte povera estetiğinin Türkiye için uygun olmadığını düşünmektedir. Beuys’un sanatını sıcak olarak tarif etmiştir. İletişimsizliğin ve edilgenliğin hâkim olduğu kuzey ülkelerinde eylemin insani boyutunu ortaya çıkaran sosyal plastik yaklaşımı Cengiz’e

43 Bek, “1970-1980 Yılları Arasında Türkiye'de Kültürel ve Sanatsal Ortam,” 75.

44 Güher Gamze Rastgeldi, “Türkiye’de Çağdaş Sanat Piyasasının Gelişimi: 2001 Krizi ve İktisat Bankası Koleksiyonunun Satılışı”, 60.

45 Vasif Kortun, 20, 21-22.

46 Erden Kosova, "Babamın Vasiyeti," Cengiz Çekil: 21.08.1945-10.11.2015, (SALT/Garanti Kültür AŞ, İstanbul, 2018), 165.

47 SALT Araştırma Cengiz Çekil Arşivi, SALT Araştırma Cengiz Çekil Arşivi, erişim 17 Ocak 2020, https:// archives.saltresearch.org/handle/123456789/51404 
göre Türkiye'ye uygun değildir. Sanatçı, Amerikan sanatını soğuk ve ketum olarak değerlendirmiş ve Beuys'un bunun peşine takılmamasını onurlu bir davranış olarak nitelendirmiştir. Fakat Türkiye gibi gündemin sürekli sıcak, her an hareketli olduğu bir ülkede bunun bir etki yaratmayacağını belirtmiştir ${ }^{48}$.

Benzer şekilde arte povera estetiğinin de bu coğrafyada farklılaşması gerektiğini söylemiştir. Çekil'e göre Türkiye'de neredeyse sokaktaki her şey arte povera'nın ulaşmaya çalıştığı ham estetiğe sahiptir ${ }^{49}$. Çekil'in bu sanatsal yaklaşımı sergideki çalışmasında da görülebilmektedir. Bu sergiden iki ay sonra Türk Amerikan Derneğinin sanat galerisinde yaptığı kişisel sergi de bu izleğin bir parçasıdır. Çekil'in üretimlerinin hızlandığı bu dönemde İzmir'de bir çağdaş sanat ortamı ve izleyicisi oluşturmak amacıyla gerçekleştirdiği sergilerde önemli kavramsal sanatçılar ${ }^{50}$ yer almıştır. İzmir'de oluşan bu sınırlı çağdaş sanat ortamının 1990'lara gelindiğinde biraz daha yaygınlaşmaya başladığını söyleyebiliriz. 1994-1995 yılları arasında Mimar Merih Dönmez'in inşaatını yaptığı bir binanın girişi Şantiye Galeri olarak Çekil'in düzenlediği çağdaş sanat sergilerine ev sahipliği yapmıştır. Şantiye Galeri'de gerçekleştirilen sergilerde, Canan Beykal gibi deneyimli isimlerin çalışmalarının yanı sıra çağdaş sanat ortamında yeni tanınan Güven İncirlioğlu, Hüseyin Bahri Alptekin, Selim Birsel, Vahap Avşar'ın çalışmaları da yer almıştır. 1990'lardaki bu sergilerin öncülü 1986'da gerçekleştirilen Joseph Beuys 'un Anısına sergisidir.

\section{Joseph Beuys'un Anısına Sergisi ${ }^{51}$}

1970’li yıllarda Cengiz Çekil Paris’te Étienne Martin atölyesinde eğitim alırken Joseph Beuys'u tanımaya ve takip etmeye başlamıştır. 1974 yazında Almanya tatilinde Beuys'un atölyesini ziyaret etmiş, kendisiyle görüşemese de öğrencileriyle tanışma firsatı bulmuştur. ${ }^{52}$ Sanatçının Beuys merakı bu serginin ortaya çıkışında belirleyicidir. Beuys'un ölüm haberini Cumhuriyet gazetesinde okuyan sanatçı o anı; "sanki ustamı kaybetmiş gibi üzüldüm” diyerek ifade etmiştir. Çekil bu ölüm haberinin kısa bir gazete haberiyle geçiştirilmesini istememiştir. Bunun üzerine ertesi gün üniversiteye gittiğinde resim bölümü atölyesinde bir yükselti üzerinde mum yakmış, yanına karanfil koymuştur. Beuys'un doğum ve ölüm tarihlerinin yer aldığı bir posterle, resimlerinin

48 “Beuys ve Biz," SALT Araştırma Cengiz Çekil Arşivi, erişim 17 Ocak 2020, https://archives.saltresearch. org/handle/123456789/47798

49 Kosova, "Babamin Vasiyeti," 144.

50 Canan Beykal, Serhat Kiraz, Ayşe Erkmen, İsmail Saray, Füsun Onur, Pierre Bernard, Osman Dinç, Erdağ Aksel, Ann Aksel (Dorsey).

51 “Joseph Beuys’un Anısına Bir Başka Sanat Toplu Sergi Gösteri” etkinliği 10-23 Mart 1986 tarihinde İzmir Alman Kültür Merkezi’nde gerçekleştirilmiştir. Sergiye katılan sanatçılar: Necati Abacı, Halil Akdeniz, Ann B. Aksel, Erdağ Aksel, Turgut Aldemir, Hüseyin B. Alptekin, Vahap Avşar, Zafer Aytekin, Canan Beykal, Michael Bishop, Lynn Criswell, Cengiz Çekil, Osman Dinç, Ahmet Elhan, Ayşe Erkmen, Adem Genç, Serhat Kiraz, Ahmet Koman, Füsun Onur, Ahmet Öktem, Mümtaz Sağlam, Fevzi Saydam, Sarkis, Yusuf Taktak.

52 Erden Kosova, “...et la résistance,” Cengiz Çekil: 21.08.1945-10.11.2015, (SALT/Garanti Kültür AŞ, İstanbul, 2018), 51. 
yer aldığ bir posteri asarak bir yerleştirme yapmıştır. Sonra bir demet çiçekle İzmir Alman Kültür Merkezine gitmiş, Alman Büyükelçiliğine de telgraf çekmiştir. Daha sonra Beuys'un sanat anlayışının konuşulduğu ve bu sebeple yeni sanatsal eğilimlerin tartış1ldığı bir etkinlik düzenlemeyi planlamıştır ${ }^{53}$.

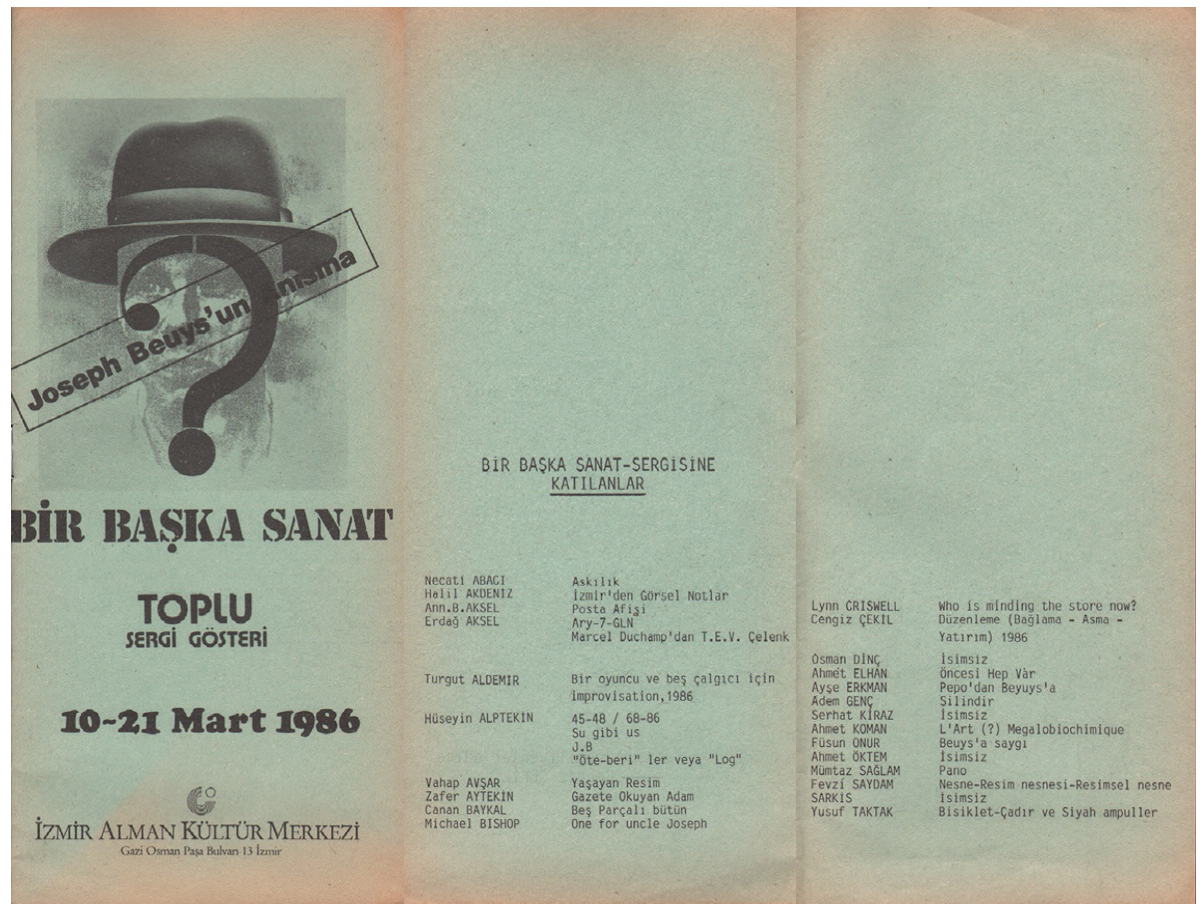

G. 1: Joseph Beuys'un Anısına Bir Başka Sanat Toplu Sergi Gösteri sergisi broşürü, (SALT Araştırma Cengiz Çekil Arşivi, https://archives.saltresearch.org/handle/123456789/51404)

İzmir Alman Kültür Merkezinin desteği ile ortaya çıkan Joseph Beuys 'un Anısına - Bir Başka Sanat Toplu Sergi Gösteri başlığı da bu etkinlik fikrini işaret etmektedir (G. 1). Sergideki sanatçıların kısa bir sürede belirlenmesi ve davet edilmesi konusunda Erdağ Aksel, Çekil'e destek vermiştir. Çekil tarafından Fransa'daki Osman Dinç ve Sarkis'e davet gönderilmiştir. Erdağ Aksel, Serhat Kiraz ve onun çevresindeki kavramsal çalışmalar üreten sanatçılara haber vermiştir. Çekil, Füsun Onur, Ayşe Erkmen, Canan Beykal, Ahmet Öktem gibi sanatçılara davet mektubu göndermiştir. Sorbonne'daki felsefe eğitimini bitirerek İzmir'e yeni gelen Hüseyin Bahri Alptekin çocukluk arkadaşı Erdağ Aksel sayesinde sergiden haberdar olmuş ve sergiye katılmak istemiştir ${ }^{54}$.

Serginin kısa sürede, sanatçılar tarafından organize edilmesi, sergi broşüründe yer alan manifestoda belirtilen yeni bir sanat arayış1, 1980'lerde tartış1lan sanat meseleleri ile de doğrudan ilişkilidir. Serginin broşüründe sergileyenler adına Cengiz Çekil'in

53 Kosova, "Babamin Vasiyeti," 143.

54 Kosova, "Babamın Vasiyeti," 146-147. 
yazdığı kısa bir metin yer almaktadır. Bu metinde bu sergiden sonra nasıl ilerleyeceği belli olmasa da resim, heykel gibi geleneksel disiplinler yerine Çekil kendi ifadesiyle bilinen malzeme ve tekniklerin dişında başka malzeme ve tekniklerle icra edilen sanat olarak sergiye adını veren Bir Başka Sanatı önermektedir:

"Bu sanatsal etkinlik, bir başlangıç bir ilk adımdır. İlerde düşünsel temelleri, çıklş noktaları, ilkeleri ve kuramıla, bir grup ya da grupların oluşması umuduyla atılmış bir ilk adımdır. Ĕger bu tür etkinlikler en az diğerleri kadar, toplu ya da bireysel olarak yaygın bir biçimde ve sık sı yinelenerek sürdürülmezse, arada sırada ve bazı VESILELERLE boy veren fantezilermiş gibi yargılanmaya MAHKÛM olurlar. Bu açıdan bütün ilk adımlarda olduğu gibi, bu etkinlik de bir ilk adım olarak kalma şansızlı̆̆ına gebedir. Ama herşeye karşın bu adımın atılması da, devamı için bir zorunluluktu" ${ }^{55}$.

Çekil'in bilinen malzeme ve tekniklerin dışında icra edilen sanatı öneren yaklaşımı, Joseph Beuys 'un Anısına sergisinin ardından Türk-Amerikan Derneği Galerisi'nde art arda yıllarda gerçekleştirilen Toplu Sergi I (1987) ve Toplu Sergi II'nin (1988) habercisidir. Bu iki sergi de yeni eğilimlerin gösterildiği faaliyetlerdir. Bundan dolayı Çekil'in ifadesinde yer alan ilk adım gerçekleştirilmiş gibidir. Ayrıca bu sanatçıların bir kısmı İzmir'de ve İstanbul'da bu sergi sonrası gerçekleşen önemli çağdaş sanat sergilerinde ortak hareket etmiştir. ${ }^{56}$ Fakat sergide yer alan sanatçıların tamamı için ortak bir yaklaşım olduğu söylenemez.

Joseph Beuys'un Anısına sergisinde yer alan isimlere bakıldığında, sanatsal tavır olarak geniş bir yelpazeye sahip olduğu görülmektedir (G. 1). Çekil'in sergi broşüründe bahsettiği ilk adım, farklı grup ya da grupların oluşması konusunda yazdıkları benzer sergilerin devam edeceğini belirten açıklamalardır. Serginin anma niteliği, geniş bir grup sanatçı ve akademisyeni bir araya getirmiştir. Sergide yer alan tüm sanatçılar Beuys'un sanat anlayışında işler üretmemektedir ve ortak bir söyleme sahip değildir. Sergiye katılan sanatçıların Beuys'u anma gayesi dışında, sanatsal ve kültürel yaklaşımlarında ortaklıklar bulunmaktadır.

Sergiyi düzenleyen Çekil bu durumu ortak enazlar olarak sergi broşüründe ifade etmiştir. ${ }^{57} 1980$ 'lerde sanatsal etkinliklerde birbirine benzer işlerin beğeni üzerinde

55 “Joseph Beuys’un Anısına sergi broşürü,” SALT Araştırma Cengiz Çekil Arşivi, erişim 17 Ocak 2020. https:// archives.saltresearch.org/handle/123456789/51404

56 İzmir'de gerçekleştirilen Toplu Sergi 1 ve 2 dışında, İstanbul'da gerçekleştirilen A, B, C sergilerinde de bu sanatçıların birlikte yer aldı̆̆ını görmekteyiz.

57 Joseph Beuys'un Anısına sergi broşüründe ortak enazlar şu şekilde ifade edilmiştir:

"-Çevremizde yer alan sanatsal etkinliklerle; ilk bakışta birbirlerinden farklıymış gibi görünseler de temelde belirli niyetlilik ve beğeni kesişmelerinde ötürü, gelişen sanatsal duyarsızlaşmaya karşı duyulan tepki.

-Sanat yapııı/çalışması yalnızca bir süs eşyası, duvara eşyalara uyan tamamlayıcı bir dekoratif unsur olmanın ötesinde sanatsal/kültürel bir iletişim aracıdır.

-Sanat yapıtı yalnızca kârlı bir yatırım nesnesi, alım-satımıyla günlük maişetin temin edildiği kültür maskeli bir ticari emtia değil aynı zamanda bir insani/manevi değerler taşıyıcısı, bir insanın zihinsel/bedensel çabalarının ürünüdür." https://archives.saltresearch.org/handle/123456789/51404 
yarattığı sanatsal duyarsızlaşmayı, sanat eserinin dekoratif bir unsura ve/veya ticari bir emtiaya dönüşmesi gibi olumsuzlukları eleştirmişlerdir. Sanat çalışmasının sanatsal ve kültürel bir iletişim aracı olduğunun altını çizmişlerdir. Broşürde yer alan sergi yazısının tamamı bir manifesto niteliği taşımaktadır.

Manifestoda ortak enazlar başlığı altında toplanan maddelerle, 1980'li yılların kültür sanat ortamı bölümünde bahsettiğimiz kültür-sanat politikaları ve kültür-sanat sektörü ilişkilerinde görülen değişim ve yaklaşımlara karşı tutumun ortaya konduğu görülmektedir. Alternatif sanatsal yaklaşımları kapsayan, kavramsal sanata yaklaşan çağdaş sanatın dili eleştireldir. Sanat eserinin bir emtia olarak ya da süs eşyası olarak görülmesine, sanat eserinin söylem gücünü yitirmesine karşı bir tavır olarak düşünülen bu sergi, çağdaş sanatın o dönemdeki eleştirel yaklaşımını taşımaktadır. Fakat günümüzde çağdaş sanatın kültür sermayesi kapsamında ticarileştirilmesi aynı eleştirel yaklaşımı koruyamadığının bir göstergesidir. Çağdaş paradigmada sanatsal değer, nesneden yola çıkarak belirlenen bağlamlar bütünü hâline gelmiştir. Beuys'un hayat-sanat birlikteliği, çağdaş paradigmanın söylemler, eylemler, ağlar, durumlar bağlamlarıla uyumludur. Modern paradigmada hâlâ sanatsal değerin kaynağı sanat olduğu için kriterlerden söz etmek olasıdır. Kriterler yerine maddi değerler üzerinden algılanan ya da ölçülen çağdaş sanat böylece eleştirel gücünü yitirmeye başlamıştır ${ }^{58}$.

Beuys'un ölümü üzerine gerçekleştirilen sergiye İzmir Alman Kültür Merkezi destek olmuştur. Adı geçen merkezin mekân desteği dışında, serginin bütçesi sınırlıdır. Sanatçılar çalışmalarını kendi imkânları ile göndermekte, kurulumu birlikte gerçekleştirmektedirler. Bu bakımdan çağdaş sanatın kültürü özelleştiren, küresel sermayeyle ilişkilendiren sonraki örneklerinden farklıdır. Ortak enazlarda eleştirilen kültür sektörü, resim ve heykel gibi geleneksel araçlarla yapılan sanatsal üretimlerle ilgilenmektedir ve sanatı dekoratif bir unsur hâline getirmektedir. 


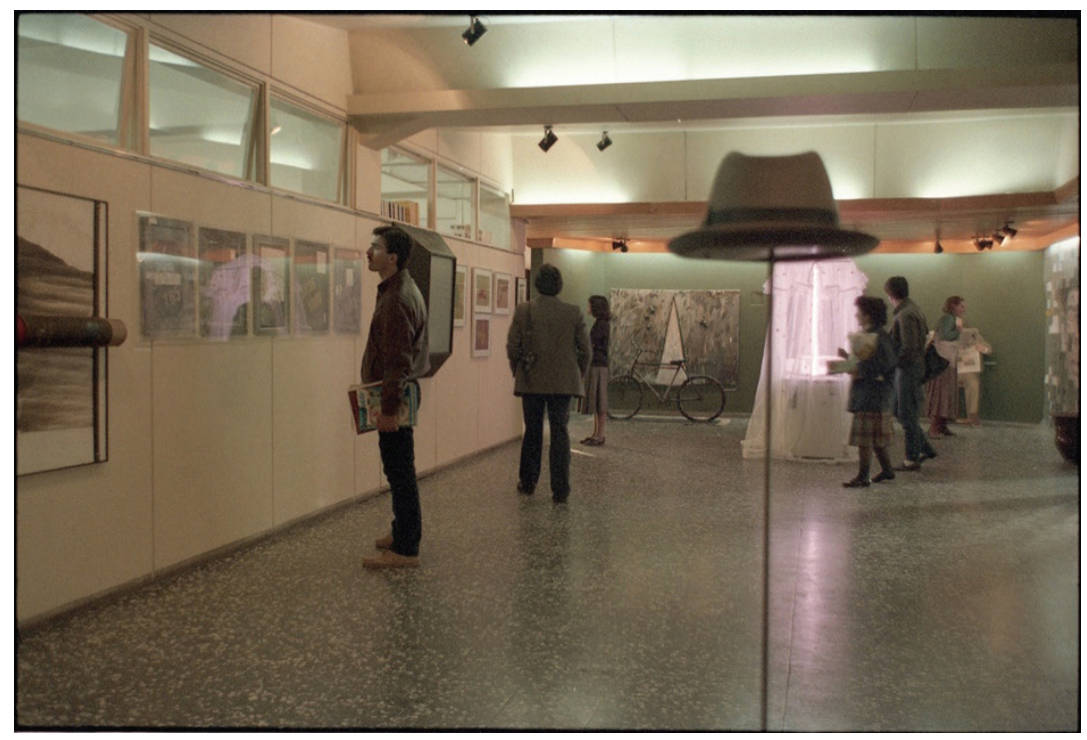

G. 2: Sergiden görünüm, İzmir Alman Kültür Merkezi Sanat Galerisi, 1986, (SALT Araştırma Serhat Kiraz Arşivi, https://archives.saltresearch.org/handle/123456789/207109)

Alman Kültür Merkezinin sergi salonu, sergileme açısından kolay bir mekân değildir. Alçak tavanlı ve görüş açısını daraltan planıyla pencere ve kolonlarıyla bu kadar çok sanatçının çalışmasını yan yana getirmenin zor olduğu G. 2.'de ve G. 3.'te görülmektedir. Alçak tavanlı bu mekânın dar ve karanlık bir giriş bölümü bulunmaktadır. Beyaz paneller, pencereler ve aydınlatma, sergi mekânı için çok uygun değildir. Sergide fotoğraf, özgün baskı, heykel, yerleştirme gibi farklı malzeme ve disiplinlerde üretilmiş çalışmalar yer almıştır. Türkiye'de geleneksel anlayıştaki resim ya da heykel dışında farklı malzeme ve disiplinlerle üretilen çalışmalar 1970'lerin sonlarından itibaren özellikle 1980’lerde görülmeye başlanmıştır. Kavramsal sanata daha yakın çalışmalar bu dönemde artmıştır.

Bu sergide yer alan sanatçılardan Ahmet Öktem ve Serhat Kiraz, 1977'de kurulan Sanat Tanım Topluluğunun kurucularındandır. Art \& Language (Sanat ve Dil) topluluğu ve Joseph Kosuth ile benzer yaklaşımlar gösteren bu gruptaki sanatçılar, sanat üzerine ortak araştırmalar yürüterek elde ettikleri sonuçları yine sanat olarak sunmuştur. 1981 yılında gruptan ayrılan Ahmet Öktem ve Serhat Kiraz'ın kavramsal çalışmaları bu tarihten sonra da devam etmiştir. Bu sergide yer alan Ahmet Öktem'in Ísimsiz (Untitled) adlı çalışması da dil ve sanat ilişkisi çerçevesinde oluşturulmuştur. 


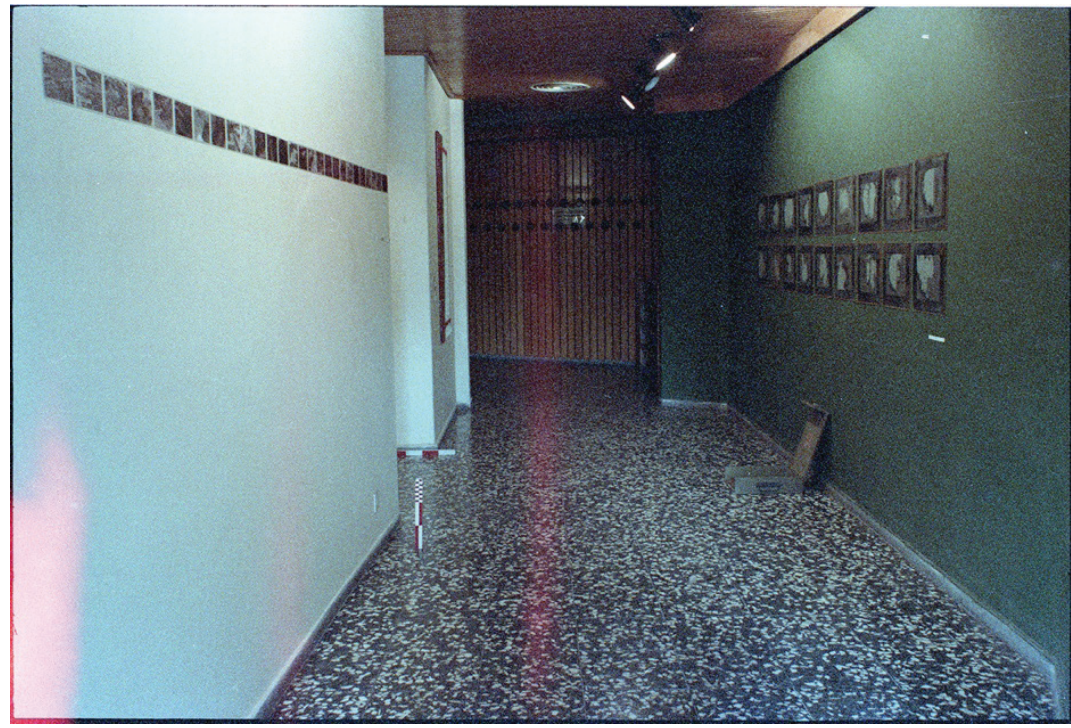

G. 3: Solda Serhat Kiraz, İsimsiz. Sağda Sarkis, İsimsiz.

(SALT Araştırma Serhat Kiraz Arşivi. https://archives.saltresearch.org/handle/123456789/207109)

Serhat Kiraz'ın İsimsiz (Untitled) adlı çalışması fotoğraflardan ve kırmızı beyaz bantlarla oluşturulmuş işaretlemelerden oluşan bir yerleştirmedir (enstalasyon). Serhat Kiraz'ın çalışmasının karşı duvarında Sarkis'in İsimsiz (Untitled) adını taşıyan bir yerleştirmesi yer almaktadır (G. 3). Arşiv fotoğraflarından çalışmanın tekniği ve ayrıntıları anlaşılamasa da bu çalışma o dönemde sanatçının odağındaki nostalji temasının etrafında geliştirilmiş gibidir. Yine aynı yıl, Maçka Sanat Galerisinde düzenlediği Çaylak Sokak ${ }^{59}$ adlı kişisel sergisinde de yirmi yıl sonra döndüğü İstanbul'a, çocukluğunun geçtiği sokağa, kişisel belleğe, ortak geçmişe ilişkin bir düzenleme yapmıştır. İstanbul'dan katılan pek çok sanatçının çalışmasıyla birlikte Sarkis' in çalışmasını da sergiye Serhat Kiraz getirmiş, sergi kurulumunda bulunmuştur ${ }^{60}$. Sarkis'in sergiye katılımının ilginç bir yanı, Cengiz Çekil'in Beuys'un yapıtlarına yoğunlaşmasında etkisinin olmasıdır ${ }^{61}$.

Joseph Beuys'un Anısına, Türkiye çağdaş sanatında yer alan önemli sanatçılardan biri olan Hüseyin Bahri Alptekin'in ilk sergisidir. Hüseyin Bahri Alptekin o tarihlerde Sorbonne'da felsefe doktorası yapmaktadır ${ }^{62}$. Alptekin, Erdağ Aksel'in çocukluk arkadaşıdır. Sanatçı, çocukluğundan beri kolaj yapmaktadır. 1970'lerde resim ve fotoğrafla

59 Sarkis'in bu çalışması ile ilgili bk. Hülya Karaçalı Annepçioğlu ve Cüney Kurt, "Bellek ve Sanat İlişkisi: Canan Tolon ve Sarkis Zabunyan”, Art-Sanat 12 (2019), 223-241, erişim 10 Ocak 2021, https://dergipark.org.tr/tr/pub/iuarts/issue/47471/598503

60 Vahap Avşar yayınlanmamış röportaj, 04 Şubat 2021.

61 Erden Kosova, “...et la résistance,” 51.

62 Vahap Avşar ve Cengiz Çekil, Cengiz Çekil Okulu (İstanbul: Ofset Yapımevi, 2020), 32. 
da ilgilenmeye başlamışıtır ${ }^{63}$. Sanatçının sergide yer alan Hommage to Joseph Beuys (Joseph Beuys'un Anısına) çalışması, J\&B marka viski etiketleri, Beuys'un bir portre fotoğrafından çoğaltılmış imgeler ve metro biletlerinden bir kolajdır (G. 4).

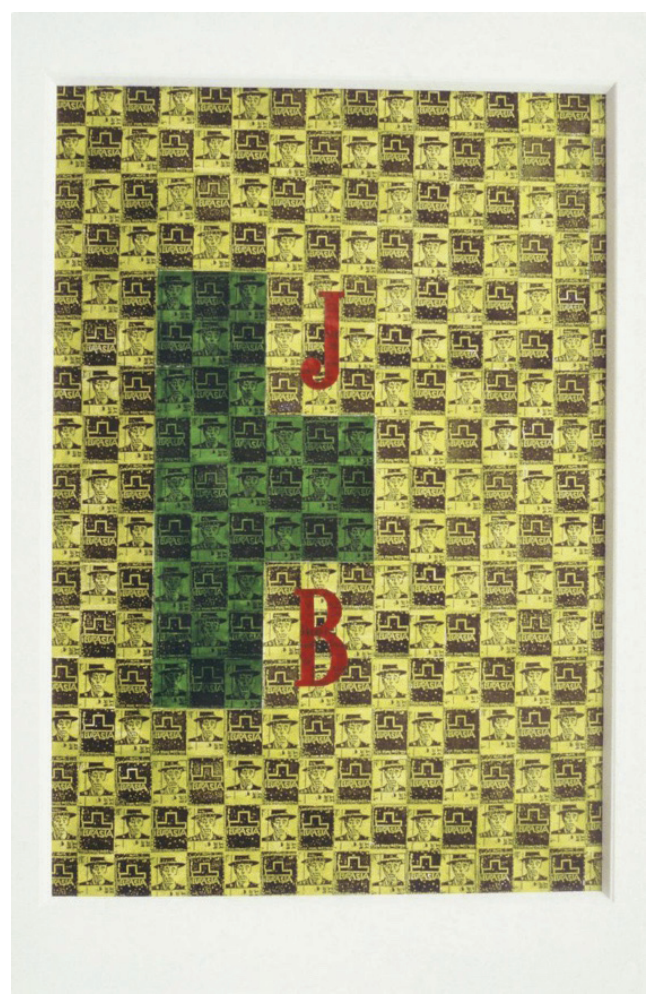

G. 4: Hüseyin Bahri Alptekin, Hommage to Joseph Beuys (Joseph Beuys'un Anısina), 1986, (SALT Araştırma Hüseyin Bahri Alptekin Arşivi, https://archives.saltresearch.org/ handle/123456789/207109)

Sanatçı 1990'larda sanat dünyasında tekrar görülmeye başlamış ve çağdaş sanatın önemli bir aktörü haline gelmiştir. Alptekin'in bu sergide yer alan çalışmasındaki kolaj tekniği, etiket kullanımı gibi sanatsal tercihleri sonraki dönem çalışmalarında da devam etmiştir. Estetik, felsefe ve sosyoloji alanlarında eğitim almış Alptekin için Beuys, "döngüsel olarak kurduğu aksiyonlarında insanlık yaralarını iyileştirmeye çalışan bir şaman şair[dir]" ${ }^{64}$. Ona göre şaman, "yaraları iyileştirirken tek şeyi ister: insanın kaybolan birliğini yeniden kurmak" ${ }^{\prime 65}$. Sergiye katılan sanatçıların birbirinden farklı sanatsal tavırlarda olsalar da bir araya gelmeleri de sanatın kaybolan birliğini yeniden kurmak ve bunun için ortak enazlarda birleşme çabasıdır. Alptekin, İzmir'de-

63 Sezin Romi, “Arşivin İzinde: Hüseyin Bahri Alptekin’e Dair,” Salt Araştırma, 15 Haziran 2017, erişim 8 Haziran 2020, https://saltonline.org/en/2047/arsivin-izinde-huseyin-bahri-alptekine-dair

64 Hüseyin Alptekin, "Şaman-Şair.” Hürriyet Gösteri Sanat ve Edebiyat Dergisi 133 (1991), 6.

65 Alptekin, "Şaman-Şair," 7. 
ki sergiden birkaç ay sonra Paris’teki Goethe Enstitüsünde, 12 Mayıs 1986 tarihinde Beuys'un doğum yıl dönümü münasebetiyle açılan bir günlük belgesel bir serginin afişinin arkasına bir not yazarak Çekil'e göndermiştir. Bu notta Paris'te Beuys'un ölümünden sonra doğum yıl dönümünde bir etkinlik yapıldığııı ve Beuys'un anısına başka bir etkinlikle karşılaşmadığını yazmıştır ${ }^{66}$.

Sergi kurulumunda Cengiz Çekil'e asistanlık eden Vahap Avşar, Dokuz Eylül Üniversitesi Güzel Sanatlar Fakültesinde birinci sınıf öğrencisidir ve Alptekin gibi onun da katıldığı ilk sergidir. Sergide yer alan Yaşayan Resim adlı çalışması dönemin sanat tartışmalarıyla yakından ilgilidir. Resmin ölümünün ilan edildiği 1980'lerde geleneksel disiplinlerle çağdaş pratikler arasındaki gerilime atıfta bulunmaktadır. Beuys'un hayat ve sanat arasındaki sınırı bulanıklaştıran yaklaşımının etkisi de bu çalışmada doğrudan görülmektedir. Vahap Avşar'ın sergide yer alan çalışması bir tuval yüzeyinin gerisine yerleştirilen 1şıklı kutunun içinde canlı bir güvencinden oluşmaktadır. Manzara resminin gerisinde kutunun içinde uçmaya çalışan güvercinin gölgesi görülmektedir. Fakat bu çalışma kurulduktan kısa bir süre sonra Goethe Enstitüsü müdürü tarafından hayvan hakları açısından olumsuz bulunmuş, çalışmanın kaldırılması ya da güvercin olmadan sergilenmesi istenmiştir. Çalışma güvercin çıkarılarak sergilenmiştir ${ }^{67}$.

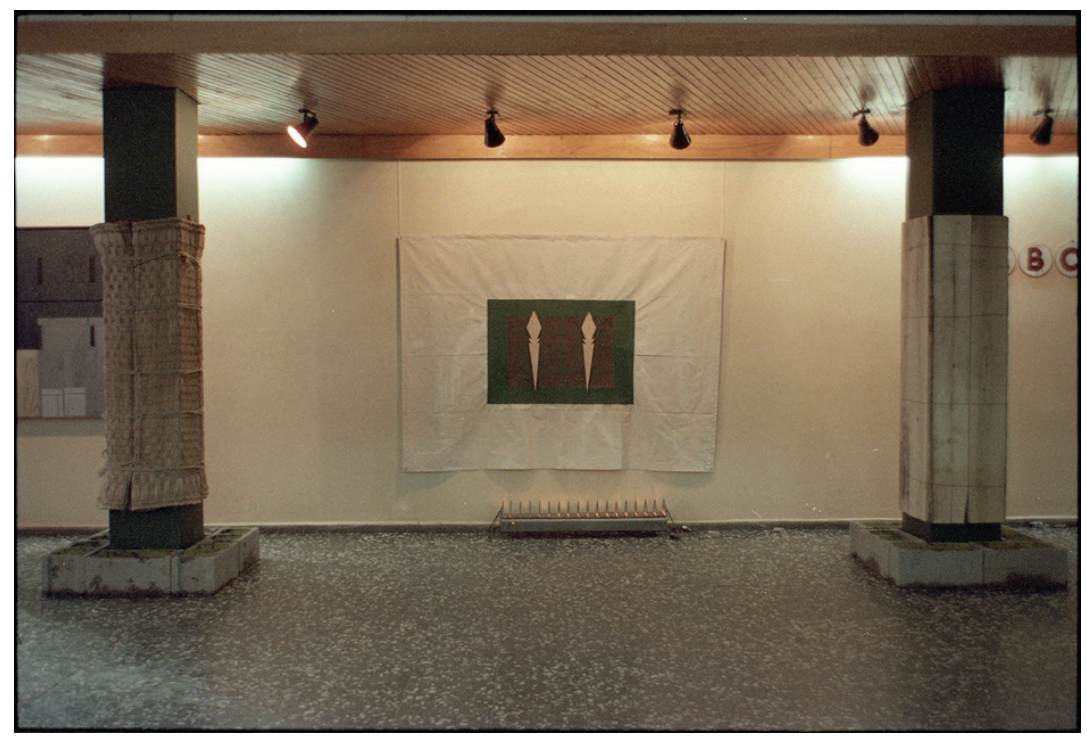

G. 5: Cengiz Çekil, "Düzenleme (Bağlama-Asma-Yatırım)"

(SALT Araştırma Serhat Kiraz Arşivi, https://archives.saltresearch.org/handle/123456789/207109)

66 “Hommage a Joseph Beuys Sergi Afiş̧i," SALT Araştırma Cengiz Çekil Arşivi, erişim 17 Ocak 2020. https:// archives.saltresearch.org/handle/123456789/49702

67 Avşar röportaj, 04 Şubat 2021. 
Cengiz Çekil'in sergide yer alan Düzenleme (Bağlama-Asma-Yatırım) adlı çalışması ölüm ve ağıtla doğrudan ilişkilidir (G. 5). Beuys'un ölümünden kısa bir süre önce bir yakının cenazesine katılan sanatçı cenaze töreninde kullanılan nesnelerle bir düzenleme oluşturmuştur. Çekil birkaç ay sonra gerçekleştireceği kişisel sergisinde Düzenleme No:2 adiyla anma, anıt fikirlerini taşıyan benzer bir yerleştirmeye rastlanmaktadır. Leonardo Da Vinci (ö. 1519), Hazerfen Ahmet Çelebi (ö. 1640), Francis Picabia (ö. 1953), Yves Klein (ö. 1962), Piero Manzoni (ö.1963), Marcel Duchamp (ö. 1968), Max Ernst (ö. 1976), Man Ray’in (ö. 1976) yanı sıra bu serginin açılmasına yakın bir tarihte kaybettiği babası Mustafa Durmuş Çekil'in de isminin yer aldığı beton üçgen prizmalardan mezar taşları üretmiştir. Mezar taşı ya da küçük anıtlar her isim için ayrılan bölümün yanına yerleştirilmiştir. Çekil'in bundan sonraki çalışmalarında ağırlıklı olarak ölüm, anıt, anma kavramları üzerine çalışmalar ürettiğini görmek mümkündür ${ }^{68}$.

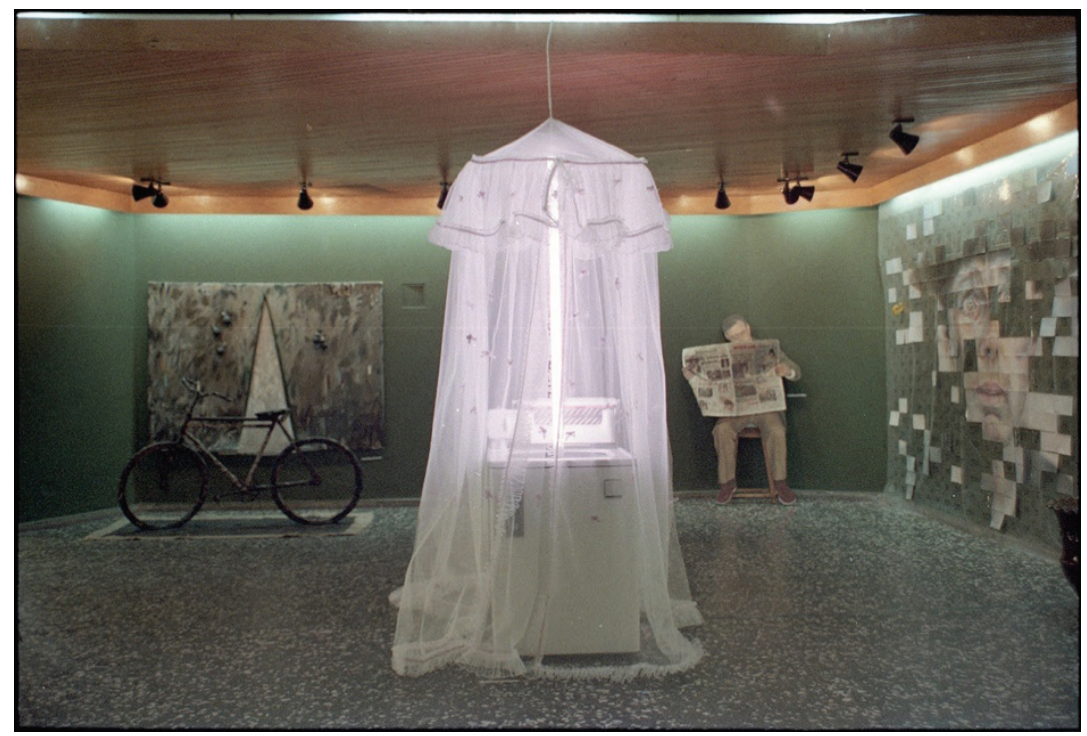

G. 6: Soldan sağa: Yusuf Taktak, "Bisiklet, Çadır ve Siyah Ampüller", Erdağ Aksel "Ary-7-

GLN", Zafer Aytekin "Gazete Okuyan Adam”, Ann B. Aksel (Dorsey) "Posta Afişi”. (SALT Araştırma Serhat Kiraz Arşivi, https://archives.saltresearch.org/handle/123456789/207385)

Yusuf Taktak, Erdağ Aksel, Zafer Aytekin ve Ann Aksel'in çalışmaları yan yana sergilenmiştir (G. 6). Ann Aksel'in Posta Afişi adlı piksellerden oluşuyormuş etkisindeki Joseph Beuys portresi, resmin sınırlarını zorlayan, tamamlanmamış bir resimle yapboz arasında gidip gelen bir yerleştirmedir. Kullanılan şeffaf plastik perde, yüzeydeki notlar, öfke (angst) kelimesinin tekrarı, henüz bitmemiş bir çalışmanın sürecini ve sanatçının üretim performansını belgeliyor gibidir. Erdağ Aksel'in Ary-7-GLN adlı düzenlemesi de heykel disiplininin sınırlarını zorlayan bir çalışmadır. Dada'dan bu yana 
hazır nesne kullanımı sanat tarihinde görülse de Türkiye için sanatın dilini sorgulayan kavramsal çalışmalar o dönem için oldukça yenilikçidir. Sergide yer alan eserleri, o dönemde yaygın bir sanatsal tavır olmayan resim ve heykelden enstalasyona doğru genişletilmiş bir alanda konumlandırabiliriz.

\section{Sonuç}

Joseph Beuys'un Anısına sergisi İzmir kültür sanat ortamında alternatif üretimlerin, yeni sanat eğilimlerinin yer aldığ ilk grup sergisidir. Bu sergi, grup sergilerinde bir ya da birkaçını görebildiğimiz söylem ortaklığı, malzeme ve teknik ortaklık, biçim ortaklığ gibi temel özelliklere kısmen sahiptir. Grup sergilerinin ortak sanat yaklaşım ve söylemlerine sahip olması bunları manifesto olarak ortaya koymaları, yenilikçi önermelerinin olması, bu sergileri kronolojik bir sanat tarihi incelemesi içinde kolaylıkla işaretlenebilmesini sağlamaktadır. Sergi için Cengiz Çekil'in yazdığı manifesto, çağdaş sanat adına çok net söylemler içeren bir grup söylemi değildir. Fakat sergide yer alan çalışmaların estetik ve etik değerlerdeki ortaklıkları, manifestoda yer alan ortak enazlar tanımlaması üzerinden değerlendirilebilmektedir. Sergide yer alan eserlerde malzeme ve teknik ortaklık bulunmasa da birbirine tezat, estetik yaklaşımlar yer almamaktadır. Günümüz çağdaş sanat anlayışının genişletilmiş alanından bakarak biçim ortaklığ̣ rahatça kurulabilir. Sergide rüştünü daha önceden ispat etmiş kolaj, fotoğraf, resim, özgün baskı gibi sanatsal anlatım alanlarıyla oluşturulan çalışmaların yanı sıra 1980'lerde kavramsal sanat, yerleştirme (enstalasyon) sanatı henüz çağdaş sanatın önemli anlatım alanlarından biri hâline gelmemişken bu alanlara ait ortaya konulan bazı çalışmaların bir arada sergilendiği görülmektedir. Bugün bu kapsamdaki bir serginin, çağdaş sanat sergisi olarak kabul edilmesi daha kolaydır. 1980'ler için bu farklı yaklaşımların yan yana olması hem biraz çelişkili hem de yenilikçi olarak tanımlanabilir.

Türk Amerikan Derneğinde gerçekleştirilen Toplu Sergi I ve Toplu Sergi II'nin bu serginin devamı niteliği taşıması ve sanatçıların yeni eğilimlere dair ortak arayışlarını devam ettirmeleri bu serginin çağdaş sanat ortamında öncü sergilerden biri olduğunun göstergesidir. Serginin diğer bir önemi de Türkiye çağdaş sanatında yer alan önemli sanatçılardan biri olan Hüseyin Bahri Alptekin'in ilk sergisi olmasıdır. İzmir çağdaş sanat ortamının oluşmasında serginin önemli bir etkisi bulunmaktadır. Sergideki çalışmalar, Joseph Beuys'un sanatsal tavrıyla doğrudan ilişkili değildir. Fakat Beuys'un sanat-hayat ayrımını ortadan kaldıran yaklaşımıyla ilişkilidir. Sergide yer alan çalışmaların genel özelliği resim ve heykel disiplinlerinin sınırlarını zorlamak ve genişletilmiş alanda yeni bir dil arayışını göstermektir. O dönem için yeni bir önerme olan bu bir başka sanat, resim ve heykele karşı alternatif teknik ve malzemeler bulmanın yanı sıra, sanatçının ve izleyicinin rolü, sanat nesnesinin statüsünü yeniden biçimlendiren ve sanat tanımını genişleten sanat eğilimleri olarak değerlendirilebilir. 
Hakem Değerlendirmesi: Dış bağımsız.

Çıkar Çatışması: Yazar çıkar çatışması bildirmemiştir.

Finansal Destek: Yazar bu çalışma için finansal destek almadığını beyan etmiştir.

Peer-review: Externally peer-reviewed.

Conflict of Interest: The author has no conflict of interest to declare.

Grant Support: The author declared that this study has received no financial support.

\section{Kaynakça/References}

Akay, Ali. Sanatın Sosyolojik Gözü. İstanbul: Bağlam Yayınları, 1999.

Alptekin, Hüseyin. “Şaman-Şair.” Hürriyet Gösteri Sanat ve Edebiyat Dergisi 133 (1991): 6-7.

Antmen, Ahu. “Küratörün 'Ne' Olduğunu Neden Tartışıyoruz?.” Sanat Dünyamız 81(2001): 101105.

Atakan, Nancy. Arayışlar-Resimde ve Heykelde Alternatif Akımlar. İstanbul: Yapı Kredi Kültür Yayınevi, 1998.

Avşar, Vahap ve Cengiz Çekil. Cengiz Çekil Okulu. Ed. Ezgi Arıduru ve Merve Elveren. (İstanbul: Ofset Yapımevi, 2020).

Aysan, Şükrü. "Uluslararası Sergilemelere Doğru.” Hürriyet Gösteri Sanat ve Edebiyat Dergisi 12 (1981): 3 .

Batur, Enis. “Küratörün Sınırında.” Sanat Dünyamız 81(2001): 95-96.

Bek, Güler. “1970-1980 Yılları Arasında Türkiye’de Kültürel ve Sanatsal Ortam.” Doktora tezi, Hacettepe Üniversitesi, 2007.

Çalışlar, Aziz. “Günümüzde Sanatsal Kültür ve Estetik.” Bilim ve Sanat Dergisi 7 (1984): 49-50.

Çalışlar, Aziz. "Sanatsal Kültürümüzde ve Sanatta Gelişme Sorunu." Bilim ve Sanat Dergisi 10 (1985): 11-13.

Çekil, Cengiz. "Beuys ve Biz.” SALT Araştırma Cengiz Çekil Arşivi. Erişim 17 Ocak 2020. https:// archives.saltresearch.org/handle/123456789/47798

Danto, Arthur C. Sanatın Sonundan Sonra-Çağdaş Sanat ve Tarihin Sinır Çizgisi. Çev. Zeynep Demirsu. İstanbul: Ayrıntı Yayınları, 2010.

Duben, İpek ve Esra Yıldız. Seksenlerde Türkiye'de Çağdaş Sanat:Yeni Açılımlar. İstanbul: Bilgi Üniversitesi Yayınları, 2008.

Evren, Süreyya. “Türkiye Güncel Sanatı Tarihini Nasıl Yazmalı.” Kullanma Kılavuzu 2.0: Türkiye'de Güncel Sanat 1975-2015. İstanbul: art-ist ve Revolver Yayınc1lık, 2015, 11-17.

Gen, Elçin. "Çağdaştan Güncele, Eserden İşe: Bir Çeviri Hikayesi.” E-Skop, 7. 8. 2012, Erişim 25 Aralık 2021. https://www.e-skop.com/skopbulten/cagdastan-guncele-eserden-ise-bir-cevirihikayesi $/ 847$

Godfrey, Tony. Conceptual Art. London: Phaidon, 1998.

Groy, Boris. Art Power. London: MIT Press, 2008.

Groy, Boris. "Politics of Installation.” e-flux Journal 2 (Ocak 2009): 1-8. Erişim 25 Aralık 2021. http://www.e-flux.com/journal/politics-of-installation/

Kortun, Vasıf. 20. İstanbul: SALT/Garanti Kültür AŞ, 2018. Erişim 17 Ekim 2020. https://saltonline. org $/ \mathrm{tr} / 1773 / 20$ 
Kosova, Erden. "Babamın Vasiyeti,” Cengiz Çekil: 21.08.1945-10.11.2015. İstanbul: SALT/Garanti Kültür AŞ, 2018, 142-203.

Kosova, Erden. “...et la résistance,” Cengiz Çekil: 21.08.1945-10.11.2015. İstanbul: SALT/Garanti Kültür AŞ, 2018, 28-74.

Krauss, Rosalind "Sculpture in the Expanded Field". The Anti-Aesthetic - Essay on Postmodern Culture. Ed. Hal Foster. Seattle: Bay Press, 1993, 31- 42.

Madra, Beral. "Küratörlüğün Sınırı Nedir?.” Radikal Gazetesi, 27 Temmuz 2001. Erişim 25 Aralık 2021. https://www.beralmadra.net/articles/radikal-gazetesi/kuratorlugun-siniri-nedir/.

Madra, Beral. İki Yılda Bir Sanat Bienal Yazıları 1987- 2003. İstanbul: Norgunk Yayıncılık, 2003.

Perniola, Mario. Sanat ve Gölgesi - Sanattan Geriye Ne Kaldı?. Çev. Kemal Atakay. İstanbul: İletişim Yayınları, 2015.

Romi, Sezin. “Arşivin İzinde: Hüseyin Bahri Alptekin'e Dair.” Salt Araştırma, 15 Haziran 2017. Erişim 8 Haziran 2020. https://saltonline.org/en/2047/arsivin-izinde-huseyin-bahri-alptekine-dair

Rastgeldi, Güher Gamze. "Türkiye'de Çağdaş Sanat Piyasasının Gelişimi: 2001 Krizi ve İktisat Bankası Koleksiyonunun Satılışı.” Yüksek Lisans tezi, Hacettepe Üniversitesi, 2019.

Rifat, Samih. "Nedir, Neyin Nesidir Küratör? Ya da Senaryo Yazarı Yönetmenliğe Soyunmalı mı?" Sanat Dünyamız 81 (2001): 97-100.

Sargon, Nursaç. “İzmir'de Güncel Sanatın Değişimi 1986-2014.” Yüksek Lisans tezi, İstanbul Bilgi Üniversitesi, 2016.

Stallabrass, Julian. Sanat A.Ş.- Çağdaş Sanat ve Bienaller. Çev. Esin Soğancılar. İstanbul: İletişim Yayınları, 2009.

Wu, Chin-Tao. Kültürün Özelleştirilmesi-1980’ler Sonrasında Şirketlerin Sanata Müdahalesi. Çev. Esin Soğancılar. İstanbul: İletişim Yayınları, 2005.

Yasa Yaman, Zeynep. “1950’li Y1lların Sanatsal Ortamı ve 'Temsil’ Sorunu.” Toplum ve Bilim 79 (1998): 94-137.

Yılmaz, Ayşe Nahide. “1980’li Yıllarda Türkiye'de Sanat ve Siyaset İlişkisi.” Doktora tezi, Hacettepe Üniversitesi, 2014.

Vahap Avşar yayınlanmamış çevrimiçi röportaj, 04 Şubat 2021.

“Joseph Beuys'un Anısına sergi broşürü.” SALT Araştırma Cengiz Çekil Arşivi. Erişim 17 Ocak 2020. https://archives.saltresearch.org/handle/123456789/51404

“Hommage a Joseph Beuys sergi afişi.." SALT Araştırma Cengiz Çekil Arşivi. Erişim 17 Ocak 2020. https://archives.saltresearch.org/handle/123456789/49702

"Sergiden görünüm, İzmir Alman Kültür Merkezi Sanat Galerisi, 1986". SALT Araştırma Serhat Kiraz Arşivi. Erişim 17 Ocak 2020. https://archives.saltresearch.org/handle/123456789/207109

“Serhat Kiraz, İsimsiz. Sarkis, İsimsiz.” SALT Araştırma Serhat Kiraz Arşivi. Erişim 17 Ocak 2020. https://archives.saltresearch.org/handle/123456789/207109

“Cengiz Çekil, Düzenleme (Bağlama-Asma-Yatırım)." SALT Araştırma Serhat Kiraz Arşivi. Erişim 17 Ocak 2020. https://archives.saltresearch.org/handle/123456789/207109

"Yusuf Taktak, 'Bisiklet, Çadır ve Siyah Ampüller', Erdağ Aksel 'Ary-7-GLN', Zafer Aytekin 'Gazete Okuyan Adam', Ann B. Aksel (Dorsey) 'Posta Afişi'.” SALT Araştırma Serhat Kiraz Arşivi, Erişim 17 Ocak 2020. https://archives.saltresearch.org/handle/123456789/207385 